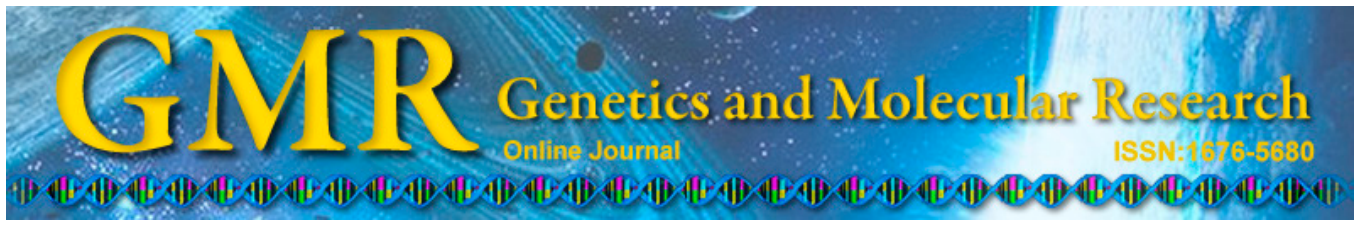

\title{
Genetic dissection of agronomic traits in Capsicum baccatum var. pendulum
}

\author{
M.M. Moulin ${ }^{1}$, R. Rodrigues ${ }^{2}$, C.S. Bento ${ }^{2}$, L.S.A. Gonçalves ${ }^{3}$, \\ J.O. Santos ${ }^{2}$, C.P. Sudré ${ }^{2}$ and A.P. Viana ${ }^{2}$ \\ ${ }^{1}$ Laboratório de Genética e Biologia Molecular, \\ Instituto Federal do Espírito Santo, Alegre, ES, Brasil \\ ${ }^{2}$ Laboratório de Melhoramento Genético Vegetal, \\ Universidade Estadual do Norte Fluminense Darcy Ribeiro, \\ Campos dos Goytacazes, RJ, Brasil \\ ${ }^{3}$ Laboratório de Melhoramento Genético Vegetal, \\ Universidade Estadual de Londrina, Londrina, PR, Brasil \\ Corresponding author: M.M. Moulin \\ E-mail: mmmoulin@ifes.edu.br
}

Genet. Mol. Res. 14 (1): 2122-2132 (2015)

Received May 20, 2014

Accepted September 23, 2014

Published March 20, 2015

DOI http://dx.doi.org/10.4238/2015.March.20.23

\begin{abstract}
Genetic mapping is very useful for dissecting complex agronomic traits. Genetic mapping allows for identification of quantitative trait loci (QTL), provide knowledge on a gene position and its adjacent region, and enable prediction of evolutionary mechanisms, in addition to contributing to synteny studies. The aim of this study was to predict genetic values associated with different agronomic traits evaluated in an $\mathrm{F}_{2}$ population of Capsicum baccatum var. pendulum. Previously, a reference genetic map for $C$. baccatum was constructed, which included 183 markers (42 microsatellite, 85 inter-simple sequence repeat, and 56 random amplification of polymorphic DNA) arranged in 16 linkage groups. The map was used to identify QTL associated with 11 agronomic traits, including plant height, crown diameter, number of days to flowering, days to fruiting, number of fruits per plant, average fruit weight, fruit length, fruit diameter, fruit
\end{abstract}


pulp thickness, soluble solids, and fruit dry weight. QTL mapping was performed by standard interval mapping. The number of small QTL effects ranged from 3-11, with a total of 61 QTL detected in 9 linkage groups. This is the first report involving QTL analysis for C. baccatum species.

Key words: Chili Pepper; Complex trait; Genetic map; Molecular markers; Quantitative trait loci

\section{INTRODUCTION}

The Capsicum baccatum species shows high genetic variability, which can be observed by the different fruit shapes, sizes, colors, aromas, textures, and pungencies (Rêgo et al., 2009), resulting in multiple uses, such as fresh fruits for in natura consumption, or dry for processing into powders or extracts (Albrecht et al., 2012).

Genetic resource studies in pre-breeding and breeding have been conducted for $C$. baccatum, which were primarily aimed at morpho-agronomic characterization and disease resistance (Rêgo et al., 2009; Rodrigues et al., 2012; Bento et al., 2013; Gonçalves et al., 2013). Additionally, interspecific crossing for gene introgression of bacterial spot disease resistance from C. baccatum into C. annuum have been successfully obtained by Potnis et al. (2012).

In addition to phenotypic information, understanding the genetic and genomic diversity of pepper species is important for assisting crop-breeding programs. Several genetic studies have been conducted for the Capsicum genus, and approaches have been based primarily on molecular marker use (Dias et al., 2013). The development of genetic maps is an important application of this technology, in which wide coverage and complete analysis of the species genome are achieved. Several genetic maps have been established for C. annuum (Lefebvre et al., 2002; Paran et al., 2004; Minamiyama et al., 2006; Barchi et al., 2007; Mimura et al., 2012; Sugita et al., 2013).

Genetic map development is very useful for assisting plant breeding programs, which allows mapping of quantitative, polygenic, or complex inherited traits, known as quantitative trait loci (QTL) (Tanksley, 1993). One of the major applications of linkage maps for crop enhancement is QTL mapping in intraspecific crossings (Chutimanitsakun et al., 2011). QTLs are genome regions responsible for quantitative trait variation, and their study enables identification and mapping of desired agronomic traits by plant breeders (Toledo et al., 2008).

QTL mapping can lead to an increased understanding of genotype and phenotype interactions. According to Bernardo (2008), QTL mapping aims to increase the knowledge of the genetic inheritance of traits and to identify molecular markers that can be used in assisted selection for relevant phenotypic traits, such as production and disease resistance.

In pepper, previous studies have been reported involving genetic parameters of plant trait series and their corresponding QTL mapping (Alimi et al., 2013). Most QTL studies in pepper have focused on commercial traits, such as fruit and production traits (Rao et al., 2003; Zygier et al., 2005; Barchi et al., 2009; Lee et al., 2011; Alimi et al., 2013) as well as studies related to identification of QTL associated with resistance to diseases (Lefebvre et al., 2003; Mimura et al., 2009; Kim et al., 2011). A limited number of studies have identified QTL associated with vegetative parts of the plant (leaves, stem internodes, and petioles) (Barchi et al., 
2009; Mimura et al., 2010).

Lee et al. (2011) located a QTL related to the pepper fruit length, located in linkage group 3, which explained $27 \%$ of trait phenotypic variation. Lu et al. (2012) identified 23 greater effect QTLs associated with 12 morphological features. A dense map consisting of 458 molecular markers was used, and the linkage map was constructed by integrating several maps published in other studies.

Alimi et al. (2013) evaluated 16 physiological traits in C. annuum species in 4 environments and identified 24 QTL. The average number of QTL per trait was 2, but ranged from $0-6$. The explained total of the trait phenotypic variance varied from 9-61\%. In the high-density map constructed by Yarnes et al. (2013), 96 QTL were estimated for 38 agronomic traits, including 12 QTL associated with capsaicinoid levels in the Capsicum population under study.

QTL enables the study of the genetic basis of traits, generating significant contributions to genomics and plant improvement. In this study, we conducted genetic dissection of QTL associated with important agronomic traits of C. baccatum.

\section{MATERIAL AND METHODS}

\section{Plant material}

Two pure lines of C. baccatum var. pendulum (UENF 1616 - $\mathrm{P}_{1}$ and UENF 1732 $\mathrm{P}_{2}$ ) from the germplasm collection of Plant Breeding Department of Universidade Estadual do Norte Fluminense Darcy Ribeiro (UENF), located in Rio de Janeiro State, Brazil, were crossed to generate $F_{1}$ (first hybrid generation) and $F_{2}$ (first $F_{1}$ selfing generation). Plants from the $\mathrm{P}_{1}, \mathrm{P}_{2}, \mathrm{~F}_{1}$, and $\mathrm{F}_{2}$ generations were evaluated and a mapping population consisting of 203 $\mathrm{F}_{2}$ individuals was used for subsequent QTL estimation.

Plants were grown under field conditions at the Research Support Unit of the Centro de Ciências e Tecnologias Agropecuárias, of UENF in Rio de Janeiro State, Brazil. Bento (2012) phenotyped this plant population and evaluated the following 11 quantitative traits: plant height; crown diameter; number of days to flowering; number of days to fruiting; number of fruits per plant; average fruit weight; fruit length (FL); fruit diameter (FD); fruit pulp thickness; soluble solids, and fruit dry weight. The data were subjected to descriptive statistical analysis and to the Pearson correlation coefficient method.

\section{Genetic mapping}

The JoinMap version 4.0 software (Van Ooijen, 2006) was used to build the integrated linkage map. Linkage groups were formed and sorted using a minimum LOD score of 3.0 and maximum of $40 \%$ recombination. Recombination frequencies were converted into genetic distances (centiMorgans) using Kosambi function (1943). Chi-square test $\left[\chi^{2}(\mathrm{P}<0.05\right.$, genetic linkage $=1)]$ was used to test the Mendelian segregation hypothesis at 1:2:1 for simple sequence repeat markers and 3:1 for inter-simple sequence repeat (ISSR) and random amplification of polymorphic DNA markers.

\section{QTL mapping}

The morphological data set for 11 quantitative traits was used to identify areas with 
potential QTL. The models described by Broman and Sen (2009) were used for QTL analysis, in which each loci marker genotype was used as a covariate effect of measured phenotypic variables. The mapping methods by standard interval allowed verification of the position of possible QTL along the linkage map estimated using the following equation:

$$
P_{i j}=\operatorname{Pr}\left(g_{i}=j / M_{i}\right)
$$

In this equation, $P_{i j}$ is the probability of QTL existence, $g_{i}$ is the possible QTL genotype, $j$ is the measured phenotypic variable, and $M_{i}$ is the marker locus genotype.

For quantitative variables, we used mapping models with standard intervals estimated using maximum likelihood algorithms of QTL existence by iterative processes, with the following equation:

$$
L(\mu \sigma)=\Pi_{i} \sum_{j} P_{i j} \Phi\left(y_{i} ; \mu_{j}, \sigma^{2}\right)
$$

(Equation 2)

In this equation, $Y_{\mathrm{i}}$ is the phenotypic value; $\hat{\mu}_{j}^{0}$ is the average of the initial phenotypic variables; and $\sigma^{2^{(0)}}$ is the initial variance of the variables.

The LOD scores were obtained using the following equation:

$$
L O D=\log _{10}\left(\frac{\prod_{i} \sum_{j} p_{i j} \Phi\left(y_{i} ; \hat{\mu}_{i}, \hat{\sigma}^{2}\right)}{\prod_{i} \Phi\left(y_{i} ; \hat{\mu}_{0}, \hat{\sigma}_{0}^{2}\right)}\right.
$$

Methods based on non-parametric models were used as multi-category variables for QTL analysis. Kruskal-Wallis test was used to evaluate the potential positions of QTL.

The probabilities of QTL genotypes were verified based on the available data on the marker genotypes. In the Kruskal-Wallis test, statistics analyzed included the sum of classes within each group of markers, which enabled calculation of the probabilities that QTL genotypes belonged to classes of markers genotypes (as described above). Next, we ranked these groups with their respective rank sums, and subsequently calculated the statistic $\mathrm{H}$ using the following equation:

$$
H=\sum_{i}\left(\frac{n-\sum_{i} p_{i j}}{n}\right)\left[\frac{\left(S_{j}-\mu_{o j}\right)^{2}}{V_{o j}}\right]
$$

(Equation 4) 
In this equation, $\mu_{0 \mathrm{j}}$ is the mean and $V_{\mathrm{oj}}$ is the variance of $S_{\mathrm{j}}$ in terms of the null hypothesis for the presence of the QTL linked to the marker locus.

Using the statistic $\mathrm{H}$, the presence of the QTL was determined after the LOD score estimates, which is a non-parametric statistic that approximately reflects the distribution of $\chi^{2}$, and may be converted to the statistics LOD $=\mathrm{H} /(2 \ln 10)$.

LOD score peaks with values greater than 1.5 were considered to be QTL-adopted. Next, the percentage of variance explained by the QTL was estimated through the "makeqtl" function package R- QTL.

\section{RESULTS AND DISCUSSION}

\section{Trait distribution and correlation}

High genetic variability among genotypes in the $\mathrm{F}_{2}$ population was observed, which was expected because the parents had very contrasting traits (Table 1). The UENF1616 parent is susceptible to pepper yellow mosaic virus (Bento et al., 2013), has an elongated fruit with a length of approximately $101 \mathrm{~mm}$, and diameter measuring $27.35 \mathrm{~m}$, and is yellow color in the immature stage and orange at maturity. The other parent, UENF 1732, is resistant to pepper yellow mosaic virus, produces pungent fruit, bell-shaped, orange color in the immature stage, red at maturity, fruit length approximately 43 , and fruit diameter of $45 \mathrm{~mm}$ (Bento et al., 2013).

\begin{tabular}{|c|c|c|c|c|c|c|c|c|c|c|c|}
\hline Statistics & $\mathrm{PH}$ & $\mathrm{CD}$ & DF1 & $\mathrm{DFr}$ & NFP & AFW & FL & FD & PT & TSS & FDM \\
\hline Mean & 1.38 & 1.40 & 84.18 & 56.07 & 100.32 & 12.81 & 68.88 & 36.42 & 2.44 & 9.28 & 2.55 \\
\hline Standard deviation & 0.20 & 0.23 & 8.76 & 6.45 & 48.08 & 3.15 & 22.67 & 8.74 & 0.43 & 1.25 & 0.56 \\
\hline Minimum value & 0.66 & 0.35 & 72.00 & 42.00 & 1.00 & 5.00 & 29.41 & 13.28 & 1.28 & 5.92 & 1.12 \\
\hline Maximum value & 1.85 & 1.87 & 119.00 & 77.00 & 317.00 & 22.56 & 135.64 & 60.19 & 3.68 & 13.40 & 4.16 \\
\hline
\end{tabular}

$\mathrm{PH}=$ plant height; $\mathrm{CD}=$ crown diameter; $\mathrm{DFl}=$ number of days to flowering; $\mathrm{DFr}=$ number of days to fruiting; $\mathrm{NFP}=$ number of fruits per plant; AFW = average fruit weight; FL = fruit length; FD = fruit diameter; PT = fruit pulp thickness; TSS = soluble solids; FDM = fruit dry weight.

A high standard deviation for the traits fruits per plant (48.08) and fruit length (22.67) was obtained, reflecting the wide variability found for these traits. A correlation study among traits was performed (Table 2), in which a positive correlation between plant height and diameter (0.604) was observed. The trait average fruit weight was positively correlated with fruit length (0.172), fruit diameter (0.178), and fruit pulp thickness $(0.180)$. These correlations were expected, as they are related to crop yield. Fruit length was negatively correlated with fruit diameter $(-0.675)$ and fruit pulp thickness $(-0.364)$. Fruit diameter and fruit pulp thickness were positively correlated $(0.620)$, which was expected.

\section{Genetic map for the $F_{2}$ population of $C$. baccatum var. pendulum}

The reference map for C. baccatum used in the QTL estimation consisted of 183 markers, including 42 (22.95\%) microsatellites, 85 (46.45\%) ISSR, and 56 (30.60\%) random amplification of polymorphic DNA, arranged in 12 larger linkage groups (321.8-110.3 cM) and 4 smaller groups $(80.8-54.2 \mathrm{cM})$, with full coverage of $2547.5 \mathrm{cM}$. 
Table 2. Phenotypic estimative and genotype correlation of $\mathrm{F}_{2}$ generation from Capsicum baccatum var. pendulum UENF 1616 x UENF 1732 crosses.

\begin{tabular}{|c|c|c|c|c|c|c|c|c|c|c|c|}
\hline Traits & PH & $\mathrm{CD}$ & DFl & DFr & NFP & AFW & FL & FD & PT & TSS & FDM \\
\hline PH & & $0.614^{* *}$ & 0.049 & -0.038 & 0.238 & 0.061 & -0.072 & -0.014 & -0.009 & -0.0003 & 0.049 \\
\hline $\mathrm{CD}$ & & & -0.027 & -0.032 & 0.539 & 0.092 & 0.022 & -0.093 & -0.025 & -0.043 & 0.055 \\
\hline DFl & & & & $0.207^{* *}$ & $-0.190 * *$ & -0.065 & 0.062 & $-0.133^{*}$ & -0.108 & -0.007 & 0.0009 \\
\hline DFr & & & & & -0.094 & 0.015 & $0.133 *$ & -0.088 & -0.084 & 0.057 & 0.522 \\
\hline NFP & & & & & & 0.005 & -0.125 & $0.258^{* *}$ & $0.315^{* *}$ & -0.124 & -0.032 \\
\hline $\mathrm{AFW}$ & & & & & & & $0.172 * *$ & $0.178^{* *}$ & $0.180 * *$ & 0.096 & -0.011 \\
\hline FL & & & & & & & & $-0.675 * *$ & $-0.364 * *$ & $0.243 * *$ & -0.068 \\
\hline FD & & & & & & & & & $0.620 * *$ & $-0.201 * *$ & 0.066 \\
\hline PT & & & & & & & & & & $-0.166^{*}$ & -0.533 \\
\hline TSS & & & & & & & & & & & 0.723 \\
\hline FDM & & & & & & & & & & & \\
\hline
\end{tabular}

***Significantly different from zero at 0.05 and $0.01 \%$ probability levels for a $t$-test, respectively. For abbreviations, see legend to Table 1.

The average distance between markers was $14.25 \mathrm{cM}$. Smaller distances indicated that the map had a higher saturation level, enabling better QTL detection. Lower results were obtained by Priyamedha et al. (2012), who found an average distance of $31.39 \mathrm{cM}$ between the markers for the genetic map constructed for Brassica carinata species.

\section{QTL mapping}

Standard interval mapping allowed for identification of QTL associated with 11 quantitative agronomic traits. The number of QTL obtained varied from 3-11 and phenotypic variation rate ranged from $0.76-3.45 \%$. The QTL average number for evaluated traits was 5.46.

Considering the 11 evaluated traits, 61 small-effect QTL were detected in 9 linkage groups (Table 3). No QTL were detected in linking groups 3, 4, and 6. Some marker loci were present in the control of more than 1 trait, particularly markers of linkage group 5b. According to Schuster and Cruz (2004), determining the number and effects of QTL can provide breeders with knowledge of the genetic control of these traits and allow for the development of more efficient selection strategies.

Alimi et al. (2013), using 149 improved recombinant lines of C. annuum, detected 24 QTL ranging from the smallest to the greatest effect for 16 agronomic traits evaluated. Yarnes et al. (2013) developed a genetic map for pepper by crossing C. frutescens and C. annuum and identified 96 QTL associated with 38 agronomic traits.

The LOD score values for most of QTL obtained using the R/QTL Package Program were critical values, which can be justified by the heritability of most agronomic traits studied, which ranged from moderate to low. Martinez et al. (1999) found that the most important factors influencing QTL power and parameters were heritability and trait genetic variance.

The identified QTL did not explain the evaluated phenotypic traits well. However, information estimating the location of QTL responsible for specific traits in C. baccatum was obtained, making this study the first to report QTL prediction for this species. Small-effect QTL are less precisely located. According to Asins et al. (2004), many QTL are small-effect, accounting for less than $10 \%$ of phenotypic variation and many of this type have been detected where the inheritance of traits under study was polygenic or quantitative. 
M.M. Moulin et al.

Table 3. QTLs detected for quantitative descriptors evaluated in $\mathrm{F}_{2}$ generation of Capsicum baccatum var. pendulum.

\begin{tabular}{|c|c|c|c|c|c|c|}
\hline Trait & Linkage group & Marker & Position (cM) & LOD score & LOD $^{\mathrm{b}}$ threshold & $\%$ of variation \\
\hline \multirow[t]{6}{*}{ Plant height $\left(\mathrm{PH}^{\mathrm{a}}\right)$} & $5 \mathrm{a}$ & 7 & 166.9 & 2.03 & 4.29 & 1.34 \\
\hline & 8 & 264 & 41.2 & 1.98 & 4.29 & 1.10 \\
\hline & 9 & 374 & 59.5 & 2.06 & 4.29 & 2.06 \\
\hline & 10 & 141 & 73.8 & 2.36 & 4.29 & 1.45 \\
\hline & $1 b$ & 371 & 17.3 & 1.89 & 4.29 & 1.45 \\
\hline & $5 b$ & 159 & 0.0 & 1.96 & 4.29 & 2.12 \\
\hline Total & & & & & & 9.52 \\
\hline \multirow[t]{8}{*}{ Canopy diameter $\left(\mathrm{CD}^{\mathrm{a}}\right)$} & $1 b$ & 371 & 17.3 & 1.75 & 3.25 & 1.25 \\
\hline & $5 b$ & 159 & 0.0 & 1.69 & 3.25 & 1.36 \\
\hline & $5 b$ & 169 & 9.0 & 1.95 & 3.86 & 0.98 \\
\hline & $5 b$ & 158 & 14.8 & 1.25 & 3.68 & 0.87 \\
\hline & $5 b$ & 144 & 21.4 & 1.36 & 3.35 & 0.96 \\
\hline & $5 b$ & 176 & 27.7 & 1.56 & 3.35 & 0.94 \\
\hline & $5 b$ & 149 & 35.5 & 1.63 & 3.35 & 1.56 \\
\hline & $5 b$ & 165 & 54.2 & 1.87 & 2.89 & 1.32 \\
\hline Total & & & & & & 9.24 \\
\hline Number of days to & 11 & 118 & 0.0 & 1.98 & 4.15 & 1.65 \\
\hline \multirow{2}{*}{ flowering $\left(\mathrm{DFl}^{\mathrm{a}}\right)$} & $5 \mathrm{~b}$ & 159 & 0.0 & 1.65 & 4.15 & 1.35 \\
\hline & $5 b$ & 165 & 54.2 & 1.55 & 4.15 & 2.01 \\
\hline Total & & & & & & 5.01 \\
\hline Number of days & 11 & 118 & 0.0 & 1.69 & 4.25 & 2.35 \\
\hline \multirow[t]{2}{*}{ to fruiting $\left(\mathrm{DFr}^{\mathrm{a}}\right)$} & $5 b$ & 159 & 0.0 & 1.96 & 4.82 & 3.45 \\
\hline & $5 b$ & 165 & 54.2 & 1.85 & 4.82 & 0.98 \\
\hline Total & & & & & & 6.78 \\
\hline \multirow{11}{*}{$\begin{array}{l}\text { Number of fruits } \\
\text { per plant }\left(\mathrm{NFP}^{\mathrm{a}}\right)\end{array}$} & $7 \mathrm{a}$ & 365 & 126.6 & 1.96 & 4.12 & 2.34 \\
\hline & 9 & 374 & 59.5 & 1.96 & 4.12 & 1.56 \\
\hline & $1 b$ & 282 & 80.2 & 1.96 & 3.36 & 0.98 \\
\hline & $2 a$ & 152 & 90.0 & 1.36 & 3.36 & 1.25 \\
\hline & $5 \mathrm{~b}$ & 159 & 0.0 & 2.15 & 3.56 & 1.36 \\
\hline & $5 b$ & 169 & 9.0 & 2.15 & 3.56 & 1.53 \\
\hline & $5 b$ & 158 & 14.8 & 2.15 & 3.56 & 1.65 \\
\hline & $5 b$ & 144 & 21.4 & 2.15 & 3.56 & 1.56 \\
\hline & $5 b$ & 176 & 27.7 & 2.15 & 3.65 & 1.69 \\
\hline & $5 b$ & 149 & 35.5 & 2.15 & 3.12 & 1.23 \\
\hline & $5 b$ & 165 & 54.2 & 1.98 & 3.56 & 0.98 \\
\hline Total & & & & & & 16.13 \\
\hline \multirow[t]{9}{*}{ Average fruit mass $\left(\mathrm{AFM}^{\mathrm{a}}\right)$} & $2 \mathrm{a}$ & 359 & 258.3 & 1.69 & 4.08 & 1.45 \\
\hline & $3 a$ & 299 & 181.1 & 1.56 & 3.65 & 2.36 \\
\hline & 12 & 316 & 43.1 & 1.48 & 3.65 & 0.96 \\
\hline & $5 \mathrm{~b}$ & 159 & 0.0 & 1.96 & 3.65 & 1.56 \\
\hline & $5 b$ & 158 & 14.8 & 1.63 & 3.65 & 1.69 \\
\hline & $5 b$ & 144 & 21.4 & 1.54 & 3.65 & 1.56 \\
\hline & $5 b$ & 176 & 27.7 & 1.96 & 3.65 & 1.56 \\
\hline & $5 b$ & 149 & 35.5 & 1.96 & 3.65 & 1.65 \\
\hline & $5 b$ & 165 & 54.2 & 1.96 & 3.65 & 1.65 \\
\hline Total & & & & & & 14.44 \\
\hline \multirow[t]{3}{*}{ Fruit length $\left(\mathrm{FL}^{\mathrm{a}}\right)$} & 11 & 118 & 0.0 & 1.96 & 4.08 & 1.98 \\
\hline & $5 b$ & 159 & 0.0 & 2.13 & 4.08 & 1.76 \\
\hline & $5 b$ & 165 & 54.2 & 2.01 & 4.08 & 1.98 \\
\hline Total & & & & & & 5.72 \\
\hline \multirow[t]{3}{*}{ Fruit diameter $\left(\mathrm{FD}^{\mathrm{a}}\right)$} & 11 & 118 & 0.0 & 2.01 & 3.79 & 1.76 \\
\hline & $5 b$ & 169 & 9.0 & 2.01 & 3.79 & 1.09 \\
\hline & $5 b$ & 149 & 35.5 & 2.01 & 3.79 & 1.87 \\
\hline Total & & & & & & 4.72 \\
\hline \multirow[t]{3}{*}{ Pulp thickness $\left(\mathrm{PT}^{\mathrm{a}}\right)$} & $7 \mathrm{a}$ & 324 & 38.3 & 2.14 & 3.95 & 1.09 \\
\hline & $5 b$ & 159 & 0.0 & 2.14 & 3.95 & 1.13 \\
\hline & $5 b$ & 165 & 54.2 & 2.14 & 3.95 & 1.09 \\
\hline Total & & & & & & 3.31 \\
\hline \multirow[t]{6}{*}{ Total soluble solids $\left(\mathrm{TSS}^{\mathrm{a}}\right)$} & $5 \mathrm{a}$ & 342 & 82.2 & 1.98 & 4.95 & 2.13 \\
\hline & $5 b$ & 159 & 0.0 & 1.98 & 2.78 & 1.96 \\
\hline & $5 \mathrm{~b}$ & 169 & 9.0 & 1.98 & 2.78 & 0.98 \\
\hline & $5 b$ & 158 & 14.8 & 1.96 & 2.78 & 0.76 \\
\hline & $5 b$ & 144 & 21.4 & 1.96 & 2.78 & 0.76 \\
\hline & $5 b$ & 176 & 27.7 & 1.96 & 2.78 & 1.02 \\
\hline
\end{tabular}

Continued on next page

Genetics and Molecular Research 14 (1): 2122-2132 (2015)

CFUNPEC-RP www.funpecrp.com.br 


\begin{tabular}{|c|c|c|c|c|c|c|}
\hline Trait & Linkage group & Marker & Position (cM) & LOD score & LOD $^{\mathrm{b}}$ threshold & $\%$ of variation \\
\hline & $5 b$ & 149 & 35.5 & 2.01 & 3.95 & 2.16 \\
\hline & $5 b$ & 165 & 54.2 & 2.01 & 3.62 & 2.34 \\
\hline Total & & & & & & 12.08 \\
\hline \multirow[t]{4}{*}{ Fruit dry mass (FDM) } & 11 & 118 & 0.0 & 1.98 & 3.23 & 1.98 \\
\hline & $1 b$ & 371 & 17.3 & 1.98 & 3.62 & 2.09 \\
\hline & $5 b$ & 159 & 0.0 & 1.98 & 3.62 & 2.15 \\
\hline & $5 b$ & 165 & 54.2 & 1.98 & 4.62 & 3.34 \\
\hline Total & & & & & & 9.56 \\
\hline
\end{tabular}

${ }^{\mathrm{a}}$ Analysis method based on standard interval for parametric data. ${ }^{\mathrm{b}}$ Determined by permutation test at $5 \%$ probability.

Greater saturation of the linkage map may enable the QTL obtained in this study and further explain the effect of the trait or, as additional QTL are identified, higher efficiency rates may enable marker-assisted selection. Six markers were identified for plant height, located in 5 linkage groups: 1 in group 1b, 2 in group 5 (1 in 5a and 1 in 5b), 1 in group 8, 1 in group 9, and 1 in group 10. One of the markers was random amplification of polymorphic DNA (7), 2 ISSR (141 and 159), and 3 microsatellite (264, 371, and 374). The rate of phenotypic variation explained ranged from 1.10-2.12, totaling 9.52\%. Ben Chaim et al. (2001) identified 8 QTLs in groups $2,3,4,6$, and 8 based on a map constructed from $180 \mathrm{~F}_{3}$ families of C. annuum, corresponding to a different gene complex from C. baccatum.

Eight markers related to canopy diameter were detected and located in 2 linkage groups: 1 to group $1 \mathrm{~b}$ and 7 to group $5 \mathrm{~b}$. The marker mapped to group $1 \mathrm{~b}$ and identified as a QTL was a microsatellite, while the other markers associated with crown diameter were all ISSRs and mapped to group $5 \mathrm{~b}(144,149,158,159,165,169$, and 176). The variation explained by these markers ranged from $0.87-1.56$, accounting for $9.24 \%$.

For the number of days to flowering and number of days to fruiting, the same 3 markers were estimated: 1 in group 11 and 2 in group 5 b. Markers associated with these traits were ISSRs. The percentage of explained phenotypic variation ranged from 1.35-2.01 for number of days to flowering and from 0.98-3.45 for number of days to fruiting, totaling 5.01 and $6.78 \%$, respectively. As these are correlated traits, it was predicted that at least some of the markers should be common. Yarnes et al. (2013) identified QTL on different linkage groups as those found in this study. For number of days to flowering, QTL were observed in group 6; for number of days to fruiting, QTL were detected in group 8. In this study, we used a mapping population originated from an interspecific crossing between $C$. frutescens and C. annuum.

The largest number of markers was identified for number of fruits per plant, corresponding to a total of 11 markers. These markers were located in 5 linkage groups: 1 from group $1 \mathrm{~b}$ (282), 1 in group 2a (152), 7 in group 5b (144, 149, 158, 159, 165, 169, and 176), 1 in group 7a (365), and 1 in group 9 (374). For this trait, 3 associated markers were microsatellites $(282,365$, and 374) and 8 were ISSR $(144,149,152,158,159,165,169$, and 176). The rate of explained phenotypic variation ranged from $0.98-2.34$, totaling $16.13 \%$.

Alimi et al. (2013) also detected markers in groups 1 and 2 associated with the number of fruits per plant in C. annuum. Studies conducted by Rao et al. (2003) with C. annuum identified QTL possibly responsible for the in linkage groups 2, 3, and 11. Barchi et al. (2009) performed phenotypic characterization for this trait; however, they did not identify QTL related to the trait. 
Nine markers related to average fruit mass (AFM) were identified and were located in 4 distinct linkage groups: 1 in group 2a (359), 1 in group 3a (299), 1 in group 12 (316), and 6 in group $5 \mathrm{~b}(144,149,158,159,165$, and 176). Three of the mapped markers associated with AFM were microsatellites $(299,316$, and 359) and the remaining were ISSR. The explained variation ranged from $0.96-2.36$, corresponding to a total of $14.44 \%$ of phenotypic variation.

$\mathrm{Lu}$ et al. (2012) developed a dense map for a population of $C$. annuum and detected 3 QTL related to AFM in groups 3 and 4, explaining 30.14\% of phenotypic variation. Barchi et al. (2009) mapped QTL associated with AFM in linkage groups 3, 4, 11, and 12, while Rao et al. (2003) identified QTL in groups 1, 2, 3, 4, 8, 10, and 11, indicating that this trait is controlled by QTL located in some linkage groups.

For FL and FD, 3 markers were identified for each trait. For FL, 1 marker was identified in group 11 (118) and 2 in group $5 b$ (159 and 165). For FD, the same marker was identified in group 11, and 2 in group $5 \mathrm{~b}$ (149 and 169). All associated markers were of the ISSR type. The phenotypic variation ranged from 1.76-1.98 for FL and 1.09-1.87 for FD, totaling 5.72 and $4.72 \%$, respectively. Yarnes et al. (2013) also detected 2 QTL associated with pepper FD and 1 QTL associated with FL, all in linkage group 11. In studies carried out by Lu et al. (2012), 3 QTL were identified in the same position for FL and FD in linkage groups 4, 5, and 10. For FL and FD, the group of markers explained 10.98 and $21.44 \%$ of phenotypic variation, respectively. Additionally, regarding FL, Lee et al. (2011) obtained similar results to our study and observed QTL in groups 5 and 11. Contrasting data were obtained by Borovsky and Paran (2011), who identified a QTL with a large effect on linkage group 10 for average FL.

Considering pulp thickness, 3 markers were identified, 2 ISSR in group 5b (159 and 165 ) and 1 microsatellite in group $7 \mathrm{a}$ (324). The explained variation ranged from 1.09-1.13, totaling $3.31 \%$.

For total soluble solids, 8 markers were obtained, all located on linkage group 5, 1 in group 5a (342) and 7 in group $5 \mathrm{~b}(144,149,158,159,165,169$, and 176). One marker associated with soluble solids was a microsatellite (342), while the others were ISSRs. The explained phenotypic variation percent ranged from $0.76-2.34$, totaling $12.08 \%$. Ben Chaim et al. (2001), while studying the same trait in C. annuum, detected QTL in groups 3, 6, and 12. However, they used amplified fragment length polymorphism and restriction fragment length polymorphism markers for map building.

Four markers were identified in 3 different linkage groups for fruit dry mass, 1 microsatellite in group $1 \mathrm{~b}$ (371), 2 ISSR type in group 5b (159 and 165), and 1 ISSR type in group 11 (118). The phenotypic variation explained ranged values from 1.98-3.34, totaling 9.56. The best explanation values for the phenotype marker were obtained for this trait.

There is no information in the literature regarding identification of QTL associated to many of the traits evaluated in this study, not even for $C$. annuum, which is a widely studied species. In this context, no published studies were found for crown diameter, pulp thickness, and fruit dry mass, and thus we could not perform data comparison. For traits involving identification of QTL associated with fruit and yield, it was possible to make comparisons with other studies, but these comparisons were very limited.

In C. baccatum, we detected a large number of QTL identified in linkage group $5 \mathrm{~b}$. All QTL identified in this group had a maximum distance of $20 \mathrm{cM}$ to the next marker. The best saturation of this group may be related to the association for the markers with the control of various studied traits. This indicates that this group is involved in phenotypic variation for dif- 
ferent quantitative traits in C. baccatum, and QTL located in this group may be used to further understand the traits analyzed.

In this study, genetic dissection was performed on QTL location and their importance to each of the 11 quantitative agronomic traits in $C$. baccatum was determined. Therefore, these QTL of small magnitude are useful for assisted selection programs, as they can be used as a reference point for the species to detect greater effect QTL.

In this study, the first QTL for agronomic traits of relevant interest to crop breeding of C. baccatum var. pendulum were mapped, including QTL for yield components, which may be used as references for other QTL mapping studies. Additionally, a greater accumulation of QTL data on Capsicum is necessary, which will allow a comparative analysis and genetic characterization of morphological diversity of the genus.

\title{
ACKNOWLEDGMENTS
}

\author{
Research supported by Faperj and CNPq.
}

\section{REFERENCES}

Albrecht E, Zhang D, Saftner RA and Stommel RJ (2012). Genetic diversity and population structure of Capsicum baccatum genetic resources. Genet. Resour. Crop Evol. 59: 517-538.

Alimi NA, Bink MCAM, Dieleman JA and Nicola M (2013). Genetic and QTL analyses of yield and a set of physiological traits in pepper. Euphytica 190: 181-201.

Asins MJ, Bernet GP, Ruiz C, Cambra M, et al. (2004). QTL analysis of citrus tristeza virus-citradia interaction. Theor. Appl. Genet. 108: 603-611.

Barchi L, Bonnet J, Boudet C, Signoret P, et al. (2007). A high-resolution, intraspecific linkage map of pepper (Capsicum annuит L.) and selection of reduced recombinant inbred line subsets for fast mapping. Genome 50: 51-60.

Barchi L, Lefebvre V, Sage-Palloix AM, Lanteri S, et al. (2009). QTL analysis of plant development and fruit traits in pepper and performance of selective phenotyping. Theor. Appl. Genet. 118: 1157-1171.

Ben Chaim A, Paran I, Grube RC and Jahn M (2001). QTL mapping of fruit-related traits in pepper (Capsicum annuum). Theor. Appl. Genet. 102: 1016-1028.

Bento CS (2012). Melhoramento de Capsicum baccatum var. pendulum: Herança de Caracteres Agronômicos e Resistência ao Pepper Yellow Mosaic Virus. Doctoral thesis, Universidade Estadual do Norte Fluminense Darcy Ribeiro, UENF, Campos dos Goytacazes.

Bento CS, Rodrigues R, Goncalves LS, Oliveira HS, et al. (2013). Inheritance of resistance to Pepper yellow mosaic virus in Capsicum baccatum var. pendulum. Genet. Mol. Res. 12: 1074-1082.

Bernardo R (2008). Molecular markers and selection for complex traits in plants: learning from the last 20 years. Crop Sci. 48: 1649-1664.

Borovsky Y and Paran I (2011). Characterization of fs10.1, a major QTL controlling fruit elongation in Capsicum. Theor. Appl. Genet. 123: 657-665.

Broman KW and Sen SAA (2009). Guide to QTL Mapping with R/qtl. Springer, New York.

Chutimanitsakun Y, Nipper RW, Cuesta-Marcos A, Cistué L, et al. (2011). Construction and application for QTL analysis of a Restriction Site Associated DNA (RAD) linkage map in barley. BMC Genomics 12: 4.

Dias GB, Gomes VM, Moraes TM, Zottich UP, et al. (2013). Characterization of Capsicum species using anatomical and molecular data. Genet. Mol. Res. 12: 6488-6501.

Gonçalves LS, Rodrigues R, Diz MS, Robaina RR, et al. (2013). Peroxidase is involved in Pepper yellow mosaic virus resistance in Capsicum baccatum var. pendulum. Genet. Mol. Res. 12: 1411-1420.

Kim HJ, Han JH, Kim S, Lee HR, et al. (2011). Trichome density of main stem is tightly linked to PepMoV resistance in chili pepper (Capsicum annuum L.). Theor. Appl. Genet. 122: 1051-1058.

Kosambi DD (1943). The estimation of map distance from recombination values. Ann. Eugenetics 12: 172-175.

Lee HR, Kim KT, Kim HJ and Han J (2011). QTL analysis of fruit length using rRAMP, WRKY, and AFLP markers in chili pepper. Hortic. Environ. Biotechnol. 52: 602-613.

Lefebvre V, Pflieger S, Thabuis A, Caranta C, et al. (2002). Towards the saturation of the pepper linkage map by alignment 
of three intraspecific maps including known-function genes. Genome 45: 839-854.

Lefebvre V, Daubeze AM, Rouppe vd, V, Peleman J, et al. (2003). QTLs for resistance to powdery mildew in pepper under natural and artificial infections. Theor. Appl. Genet. 107: 661-666.

Lu FH, Kwon SW, Yoon MY, Kim KT, et al. (2012). SNP marker integration and QTL analysis of 12 agronomic and morphological traits in F(8) RILs of pepper (Capsicum annuum L.). Mol. Cells 34: 25-34.

Martinez ML, Vukasinovic N and Freeman AE (1999). Random model approach for QTL mapping in half-sib families. Genet. Select. Evol. 31: 319-340.

Mimura Y, Kageyama T, Minamiyama Y and Hirai M (2009). QTL analysis for resistance to Ralstonia solanacearum in Capsicum accession 'LS2341'. J. Jpn. Soc. Hortic. Sci. 78: 307-313.

Mimura Y, Minamiyama Y, Sano H and Hirai M (2010). Mapping for axillary shooting, flowering date, primary axis length, and number of leaves in pepper (Capsicum annuum). J. Jpn. Soc. Hortic. Sci. 79: 56-63.

Mimura Y, Inoue T, Minamiyama Y and Kubo N (2012). An SSR-based genetic map of pepper (Capsicum annuum L.) serves as an anchor for the alignment of major pepper maps. Breed Sci. 62: 93-98.

Minamiyama Y, Tsuro M and Hirai M (2006). An SSR-based linkage map of Capsicum annuum. Mol. Breed. 18: 157-169.

Paran I, van der Voort JR, Lefebvre V and Jahn M (2004). An integrated genetic linkage map of pepper (Capsicum spp.). Mol. Breed. 13: 251-261.

Potnis N, Minsavage G, Smith JK, Hurlbert JC, et al. (2012). Avirulence proteins AvrBs7 from Xanthomonas gardneri and AvrBs1.1 from Xanthomonas euvesicatoria contribute to a novel gene-for-gene interaction in pepper. Mol. Plant Microbe Interact. 25: 307-320.

Priyamedha BK, Singh G, Sangha MKK and Sangha MKK (2012). RAPD, ISSR and SSR based integrated linkage map from an F2 hybrid population of resynthesized and natural Brassica carinata. Natl. Acad. Sci. Lett. 35: 303-308.

Rao GU, Ben CA, Borovsky Y and Paran I (2003). Mapping of yield-related QTLs in pepper in an interspecific cross of Capsicum annuum and C. frutescens. Theor. Appl. Genet. 106: 1457-1466.

Rêgo ER, Rêgo MM, Finger FL and Cruz CD (2009). A diallel study of yield components and fruit quality in chilli pepper (Capsicum baccatum). Euphytica 168: 275-287.

Rodrigues R, Gonçalves LSA, Bento CS and Sudré CP (2012). Combining ability and heterosis for agronomic traits in chili pepper. Hort. Bras. 30: 266-233.

Schuster I and Cruz CD (2004). Estatística Genômica Aplicada a Populações Derivadas de Cruzamentos Controlados. Editora UFV, Viçosa.

Sugita T, Semi Y, Sawada H and Utoyama Y (2013). Development of simple sequence repeat markers and construction of a high-density linkage map of Capsicum annuum. Mol. Breed. 31: 909-920.

Tanksley SD (1993). Mapping polygenes. Аnnu. Rev. Genet. 27: 205-233.

Toledo ER, Leandro RA, Souza Júnior CL and Souza AP (2008). Mapeamento de QTLs: uma abordagem bayesiana. Rev. Bras. Biom. 26: 107-114.

Van Ooijen JW (2006). JoinMap Version 4.0: Software for the Calculation of Genetic Linkage Maps. Kyazma BV, Wageningen.

Yarnes SC, Ashrafi H, Reyes-Chin-Wo S, Hill TA, et al. (2013). Identification of QTLs for capsaicinoids, fruit quality, and plant architecture-related traits in an interspecific Capsicum RIL population. Genome 56: 61-74.

Zygier S, Chaim AB, Efrati A, Kaluzky G, et al. (2005). QTLs mapping for fruit size and shape in chromosomes 2 and 4 in pepper and a comparison of the pepper QTL map with that of tomato. Theor. Appl. Genet. 111: 437-445. 